\begin{tabular}{|c|c|}
\hline Title & Fabrication and photoelectrochemical property of tungsten(VI) oxide films with a flake-wall structure \\
\hline Author(s) & A mano, Fumiaki; Li, Ding; Ohtani, Bunsho \\
\hline Citation & $\begin{array}{l}\text { Chemical Communications, 46(16), 2769-2771 } \\
\text { https://doi.org/10.1039/0926931b }\end{array}$ \\
\hline Issue Date & $2010-0428$ \\
\hline DOC URL & http:/hdl.handle.net/2115/45358 \\
\hline Rights & Chem. Commun., 2010, 46, 2769-2771- Reproduced by permission of The Royal Society of Chemistry (RSC) \\
\hline Type & article (author version) \\
\hline File Information & CC46-16_2769-2771.pdf \\
\hline
\end{tabular}

Instructions for use 


\title{
Fabrication and Photoelectrochemical Property of Tungsten(VI) Oxide Films with a Flake-Wall Structure
}

\author{
Fumiaki Amano, ${ }^{* a, b}$ Ding Li, ${ }^{b}$ and Bunsho Ohtani ${ }^{a, b}$
}

\begin{abstract}
Efficient visible light-induced photoelectrochemical oxidation of water was achieved using a tungsten(IV) oxide $\left(\mathrm{WO}_{3}\right)$ film composed of perpendicularly oriented plate-like crystallites, a flake-wall film, prepared on a transparent conductive substrate by controlling anisotropic crystal growth of tungsten oxide hydrate $\left(\mathrm{WO}_{3} \cdot \mathrm{H}_{2} \mathrm{O}\right)$ followed by calcination.
\end{abstract}

Water splitting using solar light is a key technology for the establishment of a low-carbon society. ${ }^{1}$ Because of the positive Gibbs energy change in the water splitting, a direct one-step reaction may not proceed even though compensating energy is injected from outside the system, but it can be achieved by dividing into two parts: reduction of water to hydrogen and oxidation of water. Fujishima and Honda reported, for the first time, that photoirradiated titania and platinum electrodes could be used for the oxidation and reduction parts, respectively. ${ }^{2}$ Although such a "photoelectrochemical" cell requires additional external energy as electrical or chemical bias to compensate the potential drop due to resistance of a circuit as well as overpotentials for the redox (electron transfer) reactions, the anode and cathode can be designed and their performance can be optimized separately and individually, which is the most significant merit of photoelectrochemical systems compared with particulate photocatalytic systems. Photoelectrochemical oxidation of water to evolve molecular oxygen is induced on an n-type semiconductor electrode by valence band holes generated by band-gap excitation., ${ }^{3,4}$ Significant incident photon-to-current conversion efficiencies (IPCEs) for oxidation of water have been reported on $\mathrm{WO}_{3}$ films, which are responsive to the blue part of visible light owing to the band gap of ca. $2.6 \mathrm{eV}^{5-9}$ Nanocrystalline $\mathrm{WO}_{3}$ films prepared by sol-gel techniques possessed porous network structures consisting of well-crystallized nanoparticles exhibiting a large surface area for semiconductor/liquid junctions. Since porous electrodes require a thickness of several micrometers to maximize light absorption, ${ }^{10,11}$ the increase in thickness would increase grain boundaries, at which free electrons are scattered and recombination of photogenerated electron-hole pairs occurs, resulting in retardation of electron transfer to a back-contacted conductive substrate. , $^{8,112}$

It has been reported that films composed of perpendicularly oriented crystallites showed higher photoelectrochemical performance than that of films with nanocrystalline particles. ${ }^{11,13-16}$ For $\mathrm{WO}_{3}$, there have been few works focusing on the photoelectrochemical behavior of perpendicularly oriented crystalline films. ${ }^{16}$ Herein, for the first time, $\mathrm{WO}_{3}$ films consisting of perpendicularly oriented crystalline flakes were successfully fabricated by a wet process using anisotropic crystal growth of $\mathrm{WO}_{3} \cdot \mathrm{H}_{2} \mathrm{O}$ with a layered crystal structure. Since the crystalline flakes were oriented normal to the substrate like a wall, we named this film a flake-wall film. Figure 1a shows the crystal structure of $\mathrm{WO}_{3} \cdot \mathrm{H}_{2} \mathrm{O} .{ }^{17}$ The octahedral $\mathrm{WO}_{5}\left(\mathrm{H}_{2} \mathrm{O}\right)$ units in which a tungsten atom is surrounded by a water molecule and five oxygen atoms are horizontally connected at four corners to form a layer and the layers are stacked through hydrogen bondings. ${ }^{17} \quad$ The $(010)$ crystal plane-selective growth parallel to the layer would result in production of crystalline flakes, as has been observed as flake-like morphology of $\mathrm{WO}_{3} \cdot \mathrm{H}_{2} \mathrm{O} .{ }^{18,19}$ Figure $1 \mathrm{~b}$ shows a scanning electron microscope (SEM) image of particles prepared by solvothermal reaction of tungsten(VI) chloride $\left(\mathrm{WCl}_{6}\right)$ in ethanol at $373 \mathrm{~K}$. Each particle is an assembly of a number of crystalline $\mathrm{WO}_{3} \cdot \mathrm{H}_{2} \mathrm{O}$ flakes. If heterogeneous nucleation occurs only on a conductive substrate, self-organized crystal growth normal to the substrate is expected, since growth in other directions is terminated by collision with other flakes. In this study, a base layer of a nanocrystalline thin film was used for the enhancement of heterogeneous nucleation for the growth of perpendicularly oriented $\mathrm{WO}_{3} \cdot \mathrm{H}_{2} \mathrm{O}$ crystallites, which were then transformed to monoclinic $\mathrm{WO}_{3}$ crystallites by calcination. ${ }^{19,20}$
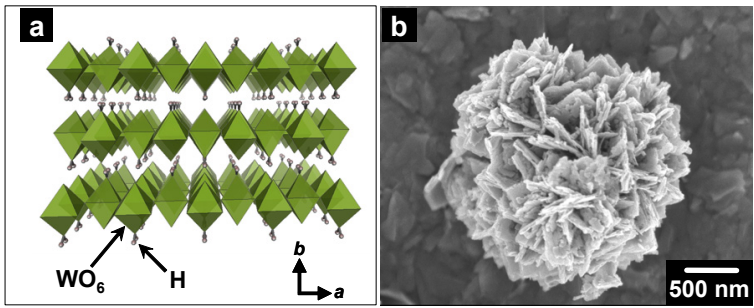

Fig. 1. (a) Crystal structure of $\mathrm{WO}_{3} \cdot \mathrm{H}_{2} \mathrm{O}$. (b) SEM image of particles prepared by solvothermal reaction of $\mathrm{WCl}_{6}$.

Tin-oxide $\left(\mathrm{SnO}_{2}\right)$-coated glass was used for a transparent conductive substrate in this study. This substrate was precoated by nanocrystalline $\mathrm{WO}_{3}$ thin films using a sol-gel technique according to the procedure by Augustynski and coworkers. ${ }^{5,6}$ The deposition of $\mathrm{WO}_{3} \bullet \mathrm{H}_{2} \mathrm{O}$ was performed using a newly developed solvothermal method. A solution of 2 mmol $\mathrm{WCl}_{6}$ in $70 \mathrm{~mL}$ ethanol was prepared in a globe box filled with dry air to avoid hydrolysis of $\mathrm{WCl}_{6}$ by atmospheric humidity. The substrate coated with a nanocrystalline $\mathrm{WO}_{3}$ thin film $\left(5.25 \mathrm{~cm}^{2}\right)$ was soaked in the ethanol solution of $\mathrm{WCl}_{6}$ and heated in a $100-\mathrm{mL}$ Teflon-lined autoclave at $373 \mathrm{~K}$ for $20 \mathrm{~h}$. No appreciable deposition was observed on the conductive glass in the absence of the base $\mathrm{WO}_{3}$ nanocrystalline layer. After cooling to room temperature, the 
substrate was washed with water and dried at $393 \mathrm{~K}$. The actual monomer for the nucleation and growth might be tungsten(VI) ethoxide produced by alcoholysis of $\mathrm{WCl}_{6}$ upon dissolution in ethanol. The film prepared by the solvothermal reaction was calcined at $773 \mathrm{~K}$ for $2 \mathrm{~h}$ in air.

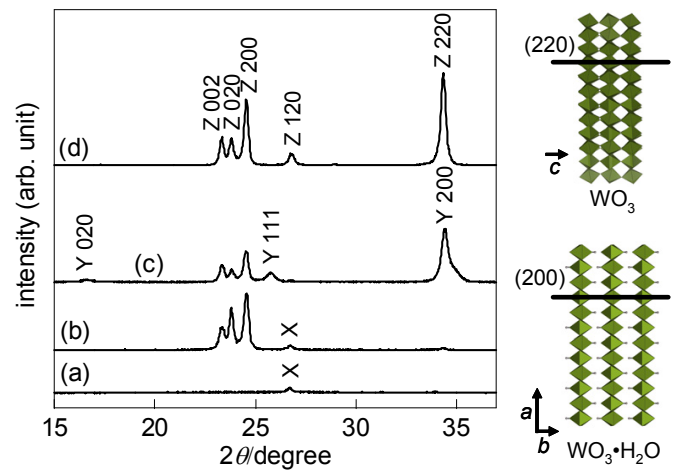

Fig. 2 XRD patterns of (a) $\mathrm{SnO}_{2}$ glass, (b) nanocrystalline $\mathrm{WO}_{3}$ thin film (c) film-A, and (d) film-B $\left(\mathrm{X}: \mathrm{SnO}_{2}, \mathrm{Y}: \mathrm{WO}_{3} \cdot \mathrm{H}_{2} \mathrm{O}\right.$, and $\mathrm{Z}$ : monoclinic $\mathrm{WO}_{3}$ ). Crystal structures of $\mathrm{WO}_{3} \cdot \mathrm{H}_{2} \mathrm{O}$ and monoclinic $\mathrm{WO}_{3}$ are also shown.

Figure 2 shows X-ray diffraction (XRD) patterns of the substrate and the prepared films. The XRD pattern of nanocrystalline $\mathrm{WO}_{3}$ thin film shows the presence of monoclinic $\mathrm{WO}_{3}$ indicated by the three characteristic diffractions at $2 \theta=23-25^{\circ}$. The film prepared by solvothermal reaction (film-A) exhibited XRD patterns assigned to crystalline $\mathrm{WO}_{3} \cdot \mathrm{H}_{2} \mathrm{O}$ (JCPDS card no. 43-0679) as well as to monoclinic $\mathrm{WO}_{3}$ corresponding to the nanocrystalline base layer. It was found that the peak intensity of $\mathrm{WO}_{3} \cdot \mathrm{H}_{2} \mathrm{O} 200$ diffraction was relatively large compared with the XRD pattern of isotropic $\mathrm{WO}_{3} \cdot \mathrm{H}_{2} \mathrm{O}$ powders, suggesting that most of the $\mathrm{WO}_{3} \cdot \mathrm{H}_{2} \mathrm{O}$ (200) planes are parallel to the substrate. Post-calcination caused disappearance of the peaks assigned to $\mathrm{WO}_{3} \cdot \mathrm{H}_{2} \mathrm{O}$ and enhancement of peaks assigned to monoclinic $\mathrm{WO}_{3}$. In the pattern of the calcined film (film-B), a peak attributable to $\mathrm{WO}_{3} 220$ diffraction exhibited high intensity, suggesting selective orientation of the (220) planes parallel to the substrate. Crystal transformation to monoclinic $\mathrm{WO}_{3}$ is considered to proceed through dehydration of hydroxyl groups in crystalline $\mathrm{WO}_{3} \cdot \mathrm{H}_{2} \mathrm{O}$. ${ }^{19,20}$

Figure 3 shows top-view images of the prepared films observed by SEM. Flake-like morphology normal to the substrate was observed for both film-A and film-B. Thus, the calcination did not change the morphology, though the average thickness of flakes was slightly reduced from ca. 95 $\mathrm{nm}$ to ca. $80 \mathrm{~nm}$ by crystal transformation inducing shrinkage of interlayer distance. An SEM cross-sectional image of filmB shows that the crystalline flakes with height of ca. $3 \mu \mathrm{m}$ were vertically deposited on the nanocrystalline $\mathrm{WO}_{3}$ thin film (ca. 0.8- $\mu \mathrm{m}$ thickness) coated on $\mathrm{SnO}_{2}$ glass. It is concluded that $\mathrm{WO}_{3}$ flake-wall films were successfully fabricated on a transparent conductive substrate using a base layer.

The photoelectrochemical property of the prepared films for water oxidation was investigated using a three-electrode system: a platinum wire as a counter electrode and a silver/silver chloride $(\mathrm{Ag} / \mathrm{AgCl})$ electrode as a reference $(+0.209 \mathrm{~V}$ vs. SHE) were used. Hereafter, the electrode potential is reported relative to the $\mathrm{Ag} / \mathrm{AgCl}$ electrode. Figure 4 shows potential-current curves under chopped visible light irradiation $(>400 \mathrm{~nm}$ ) from the back-side through the transparent substrate. The photocurrent of the nanocrystalline $\mathrm{WO}_{3}$ thin film used for preparation of the flake-wall film was relatively small and saturated at relatively low anodic potential (ca. $0.4 \mathrm{~V}$ ), suggesting poor photoabsorption ability of the base film. Film-A exhibited a dark anodic current at around $0.15-0.45 \mathrm{~V}$. The current is attributable to redox reactions of $\mathrm{WO}_{3} \cdot \mathrm{H}_{2} \mathrm{O}$ itself. The even smaller photocurrent for film-A than that of the base film indicates that $\mathrm{WO}_{3} \cdot \mathrm{H}_{2} \mathrm{O}$ was photoinactive and the solvothermal reaction diminished the photoelectrochemical activity of the base film. On the other hand, significantly enhanced photocurrent of film-B suggests that crystallization to monoclinic $\mathrm{WO}_{3}$ enhanced the photoresponse of the flake-wall film for water oxidation.

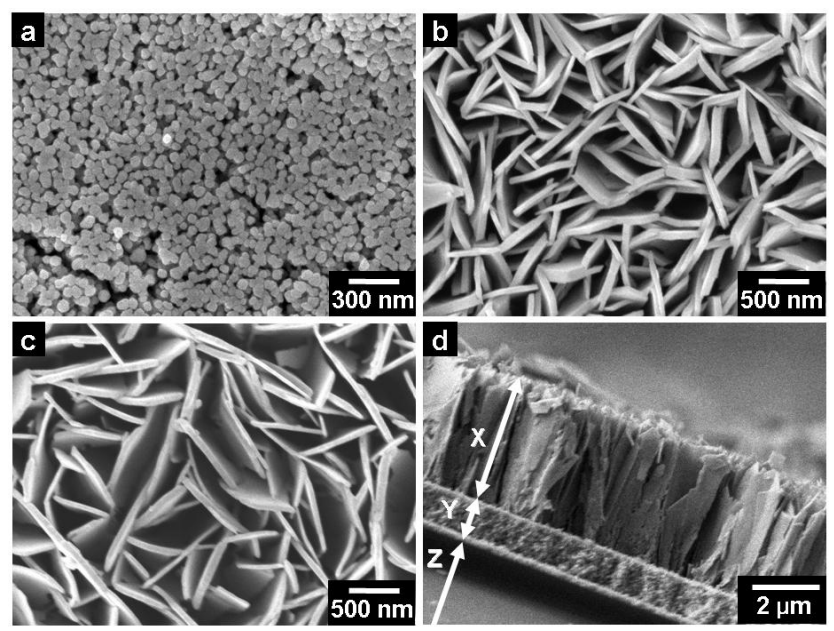

Fig. 3 SEM top-view images of (a) nanocrystalline $\mathrm{WO}_{3}$ thin film, (b) film-A, and (c) film-B. SEM cross-sectional image of (d) film-B (X: flakes, $\mathrm{Y}$ : nanocrystalline $\mathrm{WO}_{3}$, and $\mathrm{Z}: \mathrm{SnO}_{2}$ glass)
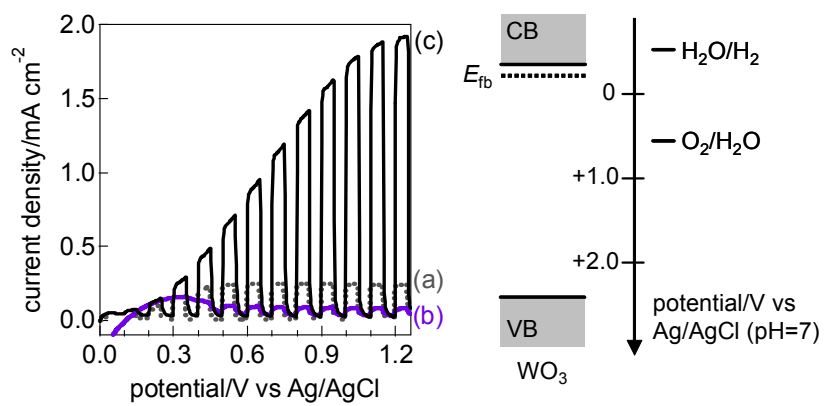

Fig. 4 Current-potential plots for (a) nanocrystalline $\mathrm{WO}_{3}$ thin film, (b) film-A, and (c) film-B illuminated with chopped visible light in an aqueous solution of $0.1 \mathrm{~mol} \mathrm{~L}^{-1}$ sodium sulfate $\left(\mathrm{Na}_{2} \mathrm{SO}_{4}\right)$. Right-side image shows an overview of the redox potentials with respect to the band potentials of $\mathrm{WO}_{3}$ at $\mathrm{pH} 7$ (CB: conduction band, VB: valence band, and $E_{\mathrm{fb}}$ : flat band potential). 
The photocurrent onset potential for film-B was observed at ca. $+0.1 \mathrm{~V}$. On the other hand, when $10 \mathrm{vol} \%$ methanol was added to the electrolyte, the onset potential shifted to cathodic potential by ca. $0.2 \mathrm{~V}$ (see Fig. S1 in ESI), which is close to the previously reported potentials for a $\mathrm{WO}_{3}$ electrode. ${ }^{5-8}$ This negative shift of the onset potential suggests that direct hole transfer to methanol to form $\mathrm{CH}_{2} \mathrm{OH}$ radical is more efficient than to water to form hydroxyl radical. ${ }^{6}$ Since the $\mathrm{CH}_{2} \mathrm{OH}$ radical exhibited the large negative redox potential, which can transfer an electron to the conduction band of $\mathrm{WO}_{3}$, the possibility of back-electron transfer is expected to be negligible. ${ }^{6}$ As previously reported ${ }^{5-8}$ the photocurrent was increased by ca. two times by the addition of methanol owing to the simple current doubling effect and/or the higher reactivity of methanol than that of water.
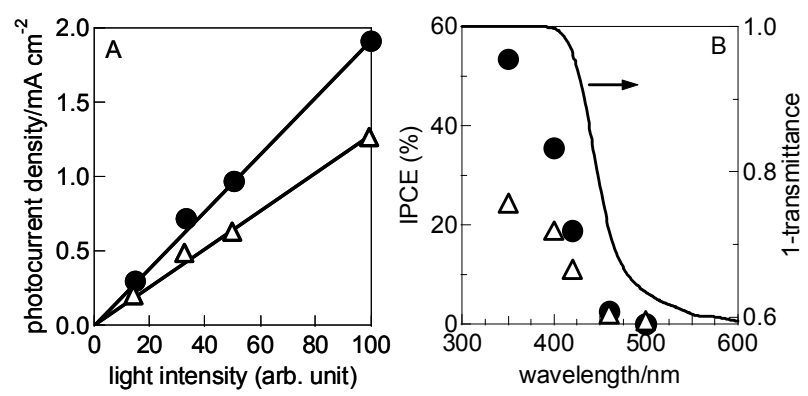

Fig. 5 (A) Photocurrent density as a function of light intensity and (B) action spectra of IPCEs for film-B (circles) and film-C (triangles) in an aqueous $\mathrm{Na}_{2} \mathrm{SO}_{4}$ solution. The photocurrent was measured at $+1.2 \mathrm{~V}$ vs $\mathrm{Ag} / \mathrm{AgCl}$. Diffuse transmittance spectrum of film-B is also shown.

Photoelectrochemical activities of film-B and a nanocrystalline $\mathrm{WO}_{3}$ thick film (film-C, thickness: ca. $3.6 \mu \mathrm{m}$, see Fig. S2 in ESI) were investigated under visible light irradiation with different light intensities (see Fig. S3 in ESI). The total weight of $\mathrm{WO}_{3}$ on film-C $(9.3 \mathrm{mg})$ was similar to that on film-B $(8.6 \mathrm{mg})$ and their absorption spectra were not so different, as shown in Fig. S4 in ESI. Figure 5A shows the photocurrent density at potential of $+1.2 \mathrm{~V}$ as a function of incident light intensity. The photocurrent for both film-B and film-C was increased proportionally with an increase in light intensity, indicating constant efficiency of charge separation under the condition of sufficient anodic polarization. The photocurrent of film-B was found to be higher than that of film-C. Such a tendency was also confirmed by photocurrent action spectrum analysis (Figure 5B). The photocurrent onset wavelength, ca. $470 \mathrm{~nm}$, was confirmed to be consistent with the bandgap of $\mathrm{WO}_{3}$ particles $(2.6 \mathrm{eV})$. The IPCEs under monochromatic $400-\mathrm{nm}$ irradiation were found to be $36 \%$ and $18 \%$ for film-B and film-C, respectively, indicating that the $\mathrm{WO}_{3}$ flake-wall film is more effective than the nanocrystalline thick film for photoelectrochemical oxidation of water. Since a nanocrystalline thick film might contain grain boundaries in high density, electron transfer is possibly suppressed compared to that in the case of crystalline flake-wall films. The actual value of IPCE $<100 \%$ indicates considerable charge recombination. Considering that the present flake-wall film requires the nanocrystalline base film (thickness: ca. 0.8 $\mu \mathrm{m})$, it would be possible to improve the photoelectrochemical property by decreasing grain boundaries in the base layer.

In conclusion, we have succeeded in preparation of $\mathrm{WO}_{3}$ flake-wall films for photoelectrochemical oxidation of water under visible light irradiation. The film exhibited efficiency higher than that of a nanocrystalline film containing a similar amount of $\mathrm{WO}_{3}$, possibly due to the relatively low density of grain boundaries in the path of electron transport and to sufficiently high photoabsorption ability and large surface area.

FA is grateful to Nissan Science Foundation, Japan for financial support. The crystal structure was visualized with the program VICS. We thank Professor Ryu Abe (Hokkaido University) for help in photoelectrochemical measurements.

\section{Notes and references}

${ }^{a}$ Catalysis Research Center, Hokkaido University, Sapporo 001-0021, Japan. Fax: +81-11-706-9131; Tel: +81-11-706-9130; E-mail: amano@cat.hokudai.ac.jp

${ }^{b}$ Graduate School of Environmental Science, Hokkaido University,

Sapporo 060-0810, Japan.

† Electronic Supplementary Information (ESI) available: Experimental details, SEM image of film-C, diffuse transmittance spectra of films, and effects of methanol addition and light intensity on the photoelectrochemical behaviors.

1 A. Kudo and Y. Miseki, Chem. Soc. Rev., 2009, 38, 253-278.

2 A. Fujishima, K. Honda, Nature, 1972, 238, 37-38.

3 M. Grätzel, Nature, 2001, 414, 338-344; M. Grätzel, Chem. Lett., 2005, 34, 8-13.

4 B. D. Alexander, P. J. Kulesza, L. Rutkowska, R. Solarska and J. Augustynski, J. Mater. Chem., 2008, 18, 2298-2303.

5 C. Santato, M. Ulmann and J. Augustynski, Adv. Mater, 2001, 13, 511-514; C. Santato, M. Odziemkowski, M. Ulmann and J. Augustynski, J. Am. Chem. Soc., 2001, 123, 10639-10649.

6 C. Santato, M. Ulmann and J. Augustynski, J. Phys. Chem. B, 2001, 105, 936-940.

7 B. Yang, P. R. F. Barnes, Y. Zhang and V. Luca, Catal.Lett., 2007, 118, 280-284; B. Yang, Y. J. Zhang, E. Drabarek, P. R. F. Barnes and V. Luca, Chem. Mater., 2007, 19, 5664-5672.

8 B. Yang, P. R. F. Barnes, W. Bertram and V. Luca, J. Mater. Chem., 2007, 17, 2722-2729.

9 M. Yagi, S. Maruyama, K. Sone, K. Nagai and T. Norimatsu, J. Solid State Chem., 2008, 181, 175-182.

10 E. L. Miller, B. Marsen, B. Cole and M. Lum, Electrochem. Solid State Lett., 2006, 9, G248-G250.

11 E. Thimsen, N. Rastgar and P. Biswas, J. Phys. Chem. C, 2008, 112, 4134-4140

12 N. S. Gaikwad, G. Waldner, A. Bruger, A. Belaidi, S. M. Chaqour and M. Neumann-Spallart, J. Electrochem. Soc., 2005, 152, G411G416.

13 N. Beermann, L. Vayssieres, S. E. Lindquist and A. Hagfeldt, J. Electrochem. Soc., 2000, 147, 2456-2461.

14 M. Law, L. E. Greene, J. C. Johnson, R. Saykally and P. D. Yang, Nature Mater., 2005, 4, 455-459.

15 S. K. Mohapatra, S. E. John, S. Banerjee and M. Misra, Chem. Mater., 2009, 21, 3048-3055.

16 H. Wang, X. Quan, Y. Zhang and S. Chen, Nanotechnology, 2008, 19, 065704(6pp).

17 J. T. Szymanski and A. C. Roberts, Can. Mineral., 1984, 22, 681688.

18 M. Niederberger, M. H. Bard and G. D. Stucky, J. Am. Chem. Soc., 2002, 124, 13642-13643; J. Polleux, M. Antonietti and M. Niederberger, J. Mater. Chem., 2006, 16, 3969-3975.

19 E. Widenkvist, R. A. Quinlan, B. C. Holloway, H. Grennberg and U. Jansson, Cryst. Growth Design, 2008, 8, 3750-3753.

20 D. L. Chen, L. Gao, A. Yasumori, K. Kuroda and Y. Sugahara, Small, 2008, 4, 1813-1822. 